\title{
DESENVOLVIMENTO DE GEMAS FÉRTEIS EM VIDEIRAS CV. ITÁLIA NO ESTADO DE SÃO PAULO $\left({ }^{1}\right)$
}

\author{
RENATO VASCONCELOS BOTELHO $\left({ }^{2}\right)$; ERASMO JOSÉ PAIOLI PIRES $\left({ }^{3}\right)$; \\ MAURILO MONTEIRO TERRA $\left({ }^{3}\right)$
}

\begin{abstract}
RESUMO
Vários trabalhos descrevem a época ou o estádio fenológico em que ocorre a formação de primórdios de inflorescência em gemas de videiras. No entanto, os relatos são bastantes diversos sobre esse assunto, possivelmente, devido às diferenças de condições climáticas entre as regiões produtoras. Neste contexto, foi desenvolvido um experimento no período de agosto de 2002 a fevereiro de 2003, com o objetivo de determinar como ocorre a formação de gemas férteis em videiras cv. Itália, nas regiões de Jales e Jundiaí (SP). A cada período de 15 dias após o início da brotação, foram amostrados cinco ramos de cada vinhedo para as avaliações. Até o $15 .^{\circ}$ nó de cada ramo, as gemas foram dissecadas e examinadas sob estéreo microscópio quanto à presença de primórdios de inflorescência. Com base nessas avaliações, foram obtidas as seguintes variáveis: porcentagem de gemas férteis a partir do estádio 5 (E5), porcentagem de gemas férteis com primórdios completamente maduros no estádio 7 (E7) e coeficiente de fertilidade dado pela relação entre número de primórdios de inflorescência/número total de gemas. A partir dos resultados, verificou-se que o início da formação dos primórdios de inflorescência (E5) ocorreu aos 30 dias após a brotação. Verificou-se a formação de primórdios de inflorescência totalmente maduros (E7), principalmente, entre 45 e 75 dias após a brotação, correspondendo aos estádios fenológicos de floração e "grão-de-ervilha" respectivamente. Na região de Jales, houve maior porcentagem de gemas férteis, independentemente da época de amostragem, possivelmente devido às maiores temperaturas médias diárias.
\end{abstract}

Palavras-chave: Vitis vinifera, uvas, fisiologia, florescimento.

\section{ABSTRACT \\ DEVELOPMENT OF FERTILE BUDS IN ‘ITALIA’ GRAPEVINE IN SÃO PAULO STATE}

Several investigations describe the time or the phenological stage of formation of the inflorescence primordial of the vine. The reports are however contradictory, possibly due to differences in climatic conditions among production regions. A trial was carried out aiming at to determine when fertile buds are developed in grapevine cv. Italia, in two production regions of São Paulo State, Brazil: Jales and Jundiaí., Five canes in each vineyard were sampled every 15 days after sprouting. Up to the $15^{\text {th }}$ node of each cane the buds were dissected and examined under stereomicroscope for presence of inflorescence primordia. Percentage of fertile buds from the stage 5 (E5), percentage of fertile buds with full mature primordial on stage 7 (E7) and coefficient of fertility (relation between number of inflorescence primordia/number of total buds) were rearded. It was verified that the beginning of inflorescence primordia (E5) occurred at the 30 days after sprouting. The formation of inflorescence primordial fully mature (E7) took place between 45 and 75 days, corresponding to the phenological stages of flowering and "pea-grain", respectively. In Jales vineyard, the percentage of fertile buds was higher, irrespective of the sample time, possibly because of its superior daily temperature averages.

Key-words:Vitis vinifera, grapes, physiology, flowering.

$\left({ }^{1}\right)$ Recebido para publicação em 30 de maio de 2005 e aceito em 27 de abril de 2006.

(2) Departamento de Agronomia, UNICENTRO. Rua Simeão Varella de Sá, 03, 85040-080 Guarapuava (PR). E-mail: rbotelho@unicentro.br. Bolsista Pós-doutorado FAPESP.

$\left({ }^{3}\right)$ Instituto Agronômico, Caixa Postal 28, 13001-970 Campinas (SP). Bolsista do CNPq. 


\section{INTRODUÇÃO}

A videira (Vitis spp.) e outros membros da família Vitaceae caracterizam-se pelo complexo de gemas axilares que inclui uma gema lateral ou gema pronta e uma gema composta, também denominada gema latente (Morrison, 1991). Em gemas latentes, formadas no ciclo vegetativo anterior à sua brotação, verifica-se em seu processo de desenvolvimento três estádios que culminam na entrada em dormência. O primeiro estádio é a formação do primórdio indiferenciado, tecido meristemático que pode diferenciar-se em primórdio de gavinha, primórdio de brotação ou ainda em primórdio de inflorescência, antes da entrada em dormência das gemas (SRINIVASAN e Mullins, 1981; Gerrath, 1992).

De acordo com Boss et al. (2003), depois de se diferenciarem, as inflorescências imaturas sobrevivem durante o inverno em estádio quiescente na gema dormente e, após a brotação das gemas, na primavera seguinte, o processo de desenvolvimento continua até a formação das flores.

Segundo SRInivasan e Mullins (1981), diversos fatores influenciam a fertilidade de gemas em videiras, tais como a característica varietal, o vigor dos ramos, a temperatura ambiente, a intensidade luminosa, o fotoperíodo, a nutrição mineral, a disponibilidade de água, os níveis endógenos de fitohormônios e as aplicações de reguladores vegetais.

Diferentes autores descrevem a época ou estádio fenológico em que ocorre a formação de primórdios de inflorescência em gemas de videiras, no entanto, os relatos são bastantes diversos sobre esse assunto. Mullins et al. (2000) citaram que a formação do primórdio indiferenciado, em condições de clima temperado, ocorre no momento da mudança da coloração dos ramos de verde para marrom e a diferenciação final em primórdio de inflorescência somente se verifica próximo da entrada das gemas em dormência.

Por outro lado, Chadha e Shikhamany (1999) relataram que, em condições de clima subtropical, a diferenciação coincide com a fase de frutificação ou pegamento de frutos e, na Índia peninsular, esse processo ocorre entre 45 e 60 dias após a poda de produção.

Essa diferença de observações pode estar relacionada à diversidade de condições climáticas entre as regiões produtoras de uvas, principalmente no que se refere à luminosidade e à temperatura. BALDWIN (1964) avaliou dados meteorológicos de uma série histórica de 18 anos e verificou que o elemento que melhor correlacionou-se com a fertilidade de gemas de videiras cv. Sultana foi o somatório de horas de luz solar entre o período de 16 de novembro e 7 de dezembro para as condições de Merbein, na Austrália, correspondendo ao início da formação dos primórdios de inflorescência.

Em trabalho realizado por Buttrose (1970) com cinco cultivares de videiras em ambiente controlado, o aumento da temperatura proporcionou um incremento do número de primórdios de inflorescência por gema e do peso dos primórdios de inflorescência, tendo sido observadas diferenças na resposta às temperaturas entre as cultivares estudadas. As cultivares de videira Riesling Renano e Shiraz iniciaram a formação de primórdios de inflorescência à temperatura de $20^{\circ} \mathrm{C}$, enquanto 'Moscatel de Alexandria' necessitou para diferenciação a temperatura de $25^{\circ} \mathrm{C}$. Normalmente, cultivares de espécies de videira americanas produzem inflorescências a temperaturas mais baixas, entre 21 e $22{ }^{\circ} \mathrm{C}$, do que cultivares da espécie Vitis vinifera, entre 27 a $28{ }^{\circ} \mathrm{C}$ (Mullins et al., 2000).

Neste contexto, este trabalho foi realizado com o objetivo de determinar a época de formação dos primórdios de inflorescência em videiras cv. Itália nas regiões de Jundiaí e Jales, no Estado de São Paulo.

\section{MATERIAL E MÉTODOS}

O experimento foi desenvolvido em dois vinhedos do cultivar Itália - um, localizado no município de Jales, Região Noroeste do Estado de São Paulo e outro em Jundiaí, na Região Leste. Em ambos os vinhedos, o sistema de condução adotado era em pérgula. Em Jundiaí, o porta-enxerto foi IAC-766 'Campinas' e em Jales, IAC-572 'Jales'.

A cada 15 dias após o início da brotação, foram amostrados cinco ramos de cada vinhedo para avaliação. O período de amostragem em Jundiaí foi de 29 de agosto a 28 de novembro de 2002. Em Jales, as amostras foram coletadas entre 4 de novembro de 2002 e 3 de fevereiro de 2003.

$\mathrm{O}$ delineamento experimental adotado foi o inteiramente casualizado no esquema de parcelas subdivididas no tempo, com dois tratamentos (locais) e cinco repetições (ramos amostrados).

As gemas basais, até o $15 .^{\circ}$ nó de cada ramo, foram cortadas transversalmente na terça parte superior, dissecadas e examinadas sob estéreomicroscópio com aumento de 45 vezes, verificando se havia presença de primórdio de inflorescência. Para essa avaliação, foram 
considerados dois estádios de desenvolvimento da inflorescência de videiras de acordo com definição de MulLins et al. (2000): (a) Estádio 5 = formação do eixo principal da inflorescência; (b) Estádio 7 = primórdio de inflorescência completamente desenvolvido, na forma de um eixo com inúmeras protuberâncias, correspondendo às futuras flores a serem formadas, assemelhando-se a um cacho de uva.

A partir dessas avaliações, foram obtidas três variáveis: porcentagem de gemas férteis a partir do estádio 5 (E5), porcentagem de gemas férteis completamente maduras no estádio 7 (E7) e coeficiente de fertilidade considerado como a relação número de primórdios de inflorescência/número total de gemas.

As temperaturas médias diárias foram levantadas para o período de 75 dias após a brotação para cada localidade, com base em dados das estações meteorológicas do Instituto Agronômico (IAC), localizadas nos municípios de Votuporanga a noroeste, e Jundiaí a leste.

Os dados obtidos foram submetidos à análise de variância para experimento em parcelas subdivididas no tempo, estudando-se a interação entre os fatores local e o tempo.

Os dados de Jales e Jundiaí puderam ser avaliados em conjunto, em razão da semelhança de sua variabilidade dentro de cada local. Os locais foram comparados pelo teste de Tukey a 5\% de probabilidade e os períodos de amostragens pela analise de regressão.

\section{RESULTADOS E DISCUSSÃO}

Para a variável porcentagem de gemas férteis a partir do estádio 5 (E5), não houve interação entre os fatores. No entanto, verificou-se significância para o fator tempo, com efeito quadrático pela análise de regressão. Observando-se a figura 1, constata-se que o início da formação do primórdio de inflorescência ocorreu a partir dos 30 dias após a brotação.

Em relação à porcentagem de gemas férteis totalmente maduras, ou seja, no estádio 7 (E7), não houve interação entre os fatores, porém, verificou-se significância para os dois fatores isolados. Na figura 1, observa-se que, para o fator tempo, houve efeito quadrático pela análise de regressão, na qual se constatou maior formação de primórdios de inflorescência entre 45 e 75 dias após a brotação, independentemente da localização do vinhedo.

No vinhedo localizado em Jales, ocorreu maior porcentagem de gemas férteis no estádio E7, independentemente da época de amostragem, estatisticamente maior ao de Jundiaí (Figura 2). Provavelmente, essa maior diferenciação de gemas férteis no vinhedo localizado na região de Jales esteja relacionada às temperaturas mais elevadas daquela região, quando comparadas àquelas registradas em Jundiaí (Figura 3). De forma semelhante, Buttrose (1970), ao trabalhar com cinco cultivares de videiras, em ambiente controlado, verificou que o aumento da temperatura incrementou o número de primórdios de inflorescência por gema e a massa média desses primórdios.

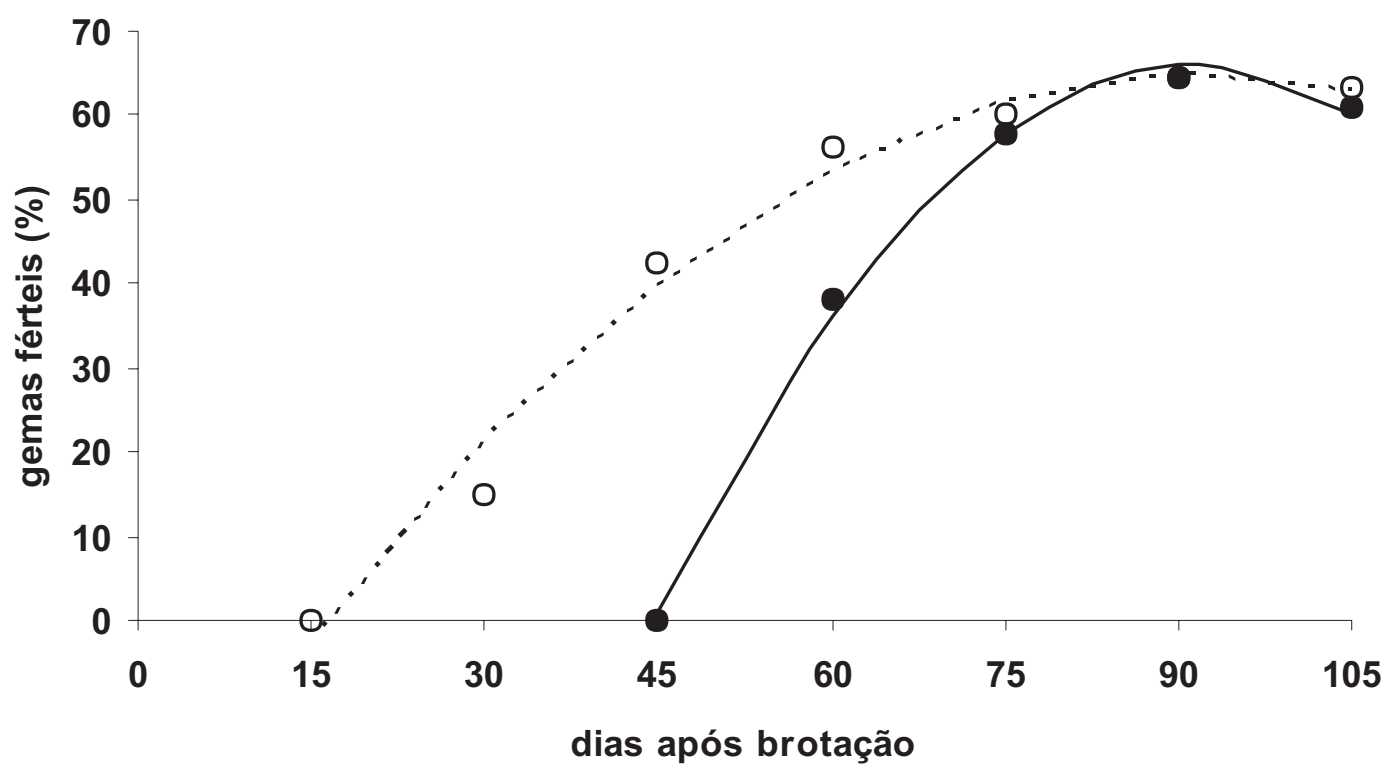

Figura 1. Porcentagem de gemas férteis a partir do estádio 5 e estádio 7 de videiras cv. Itália. 


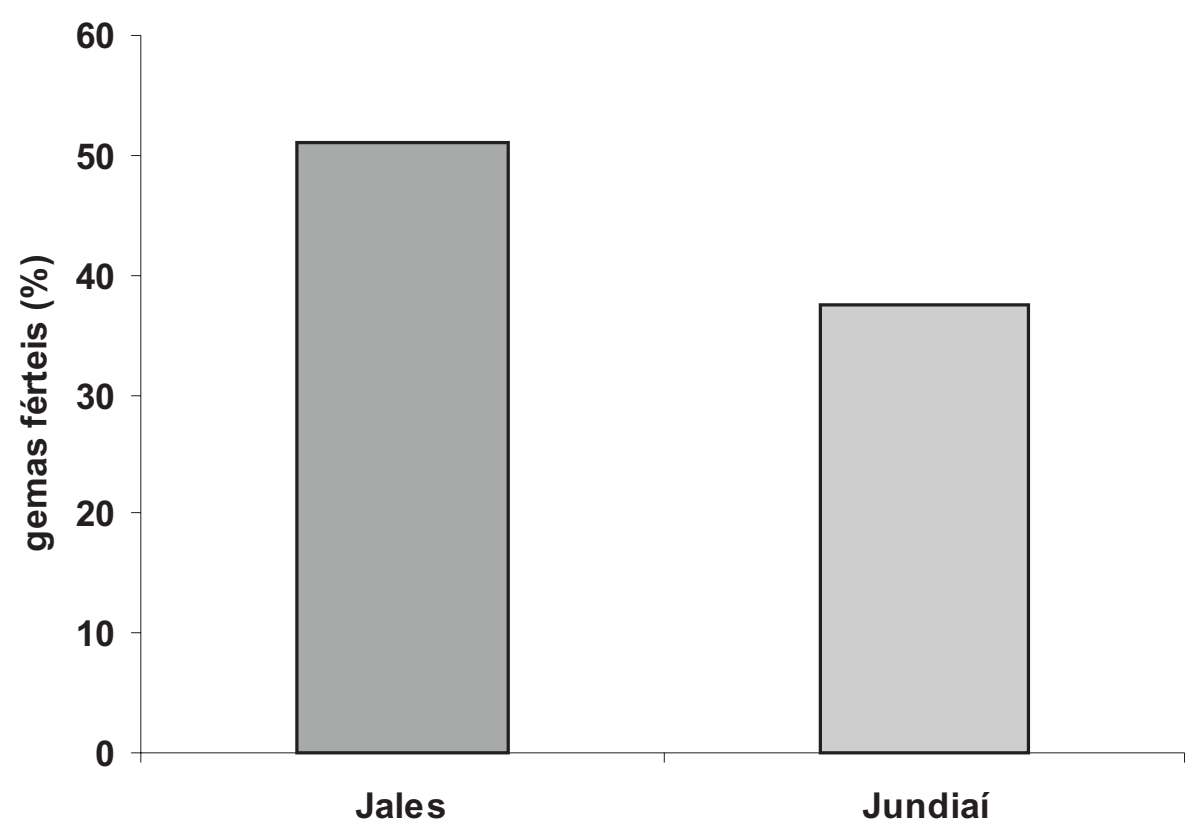

Figura 2. Porcentagem de gemas férteis de videiras cv. Itália nas regiões de Jales e Jundiaí, estatisticamente diferentes (Tukey, 5\%).

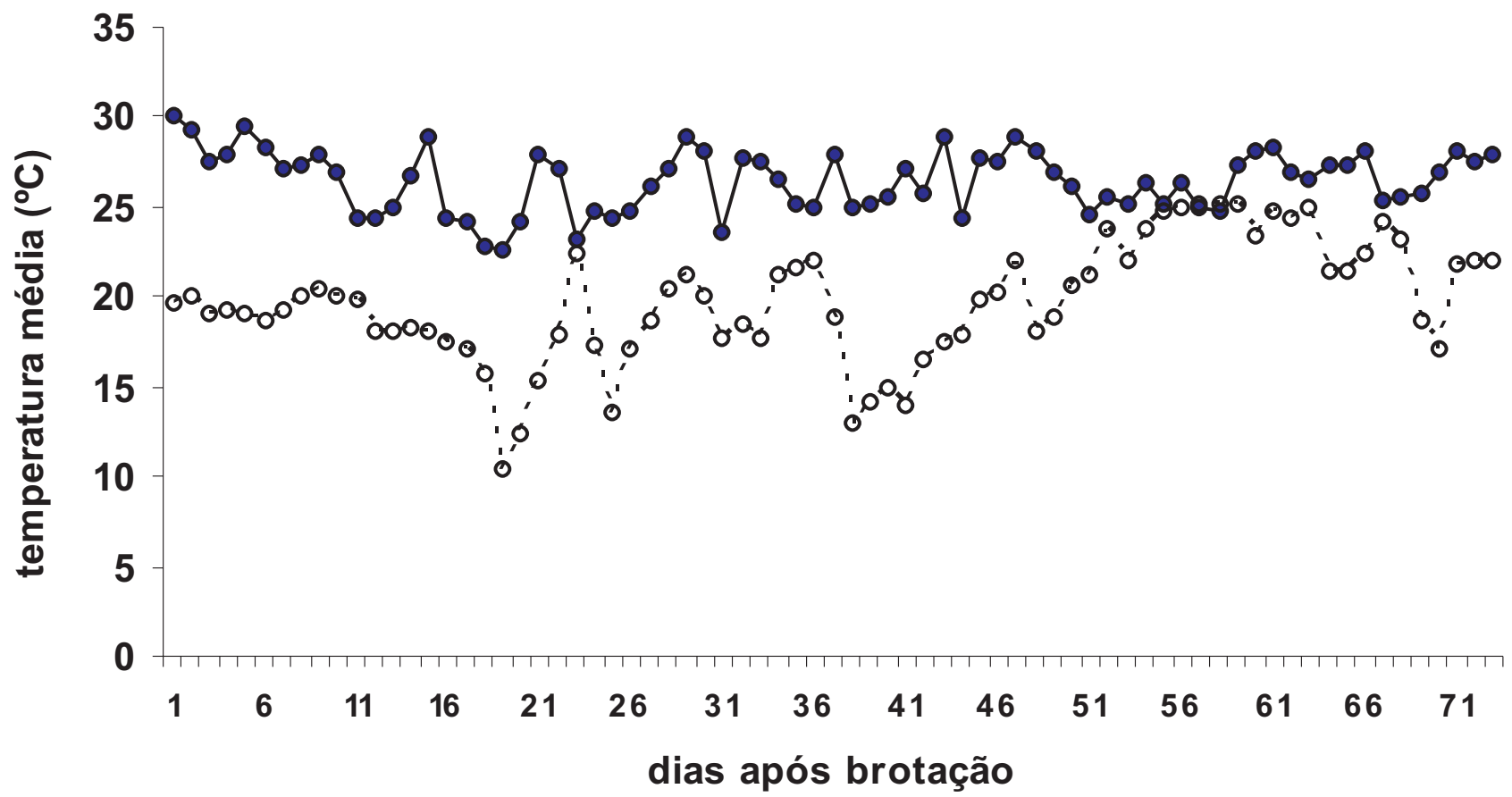

\section{$\longrightarrow$ Jales $\cdots \cdot-\cdot \cdot$ Jundiaí}

Figura 3. Temperaturas médias nas regiões de Jales e Jundiaí no período de 75 dias após a brotação de videiras cv. Itália. 
Para a variável coeficiente de fertilidade, representada pela relação número de primórdios de inflorescência/número total de gemas, verificou-se significância apenas para o fator tempo, com efeito quadrático pela análise de regressão (Figura 4). De forma semelhante à variável fertilidade de gemas com primórdios completamente maduros (E7), constatouse maior aumento do coeficiente de fertilidade entre 45 e 75 dias após o início da brotação. Entretanto, houve aumento progressivo desta variável posteriormente, até os 105 dias após brotação, devido à diferenciação de mais primórdios em uma mesma gema, tendo sido observadas gemas com até dois primórdios de inflorescência, semelhante aos relatos de Botelho et al. (2004).

Após 75 dias do início da brotação, a porcentagem de gemas férteis no estádio 7 praticamente se estabilizou, atingindo o valor de $61,7 \%$ (Figura 1), porém o coeficiente de fertilidade continuou aumentando até atingir 0,83 aos 105 dias (Figura 4).

Mullins et al. (2000) citaram que, em condições de clima temperado, a diferenciação final em primórdio de inflorescência somente ocorre próximo à entrada em dormência das gemas no inverno. Por outro lado, CHADHA e SHIKHAMANY (1999) relataram que, em condições de clima subtropical, a diferenciação coincide com a fase de frutificação ou pegamento de frutos e, em regiões tropicais, esse processo ocorre entre 45 e 60 dias após a poda de produção.
Para as condições das regiões Noroeste e Leste do Estado de São Paulo verificou-se que a formação dos primórdios de inflorescência em videiras cv. Itália se iniciou aos 30 dias após a brotação, evidenciando o estádio 5 de diferenciação floral. A maior parte do desenvolvimento em primórdios completamente maduros, ou seja, o estádio 7 , ocorreu entre 45 e 75 dias após a brotação, correspondendo ao período entre florada e estádio de "grão-de-ervilha", quando os ramos começaram a amadurecer, mudando a sua tonalidade do verde para o marrom. De forma semelhante, CHADHA e SHIKHAMANy (1999) relataram que, para as condições de clima subtropical da região norte da Índia, a diferenciação de primórdios de inflorescência ocorre durante a fase de pegamento dos frutos.

De acordo com BALDWIN (1964), o fator climático de maior correlação com a formação dos primórdios de inflorescência é o somatório do número de horas de luz solar durante essa fase. Assim, SHIKHAMANY (1999) sugeriu a realização de práticas culturais que promovam a máxima exposição dos ramos à luz solar, tais como: orientar adequadamente a posição dos ramos, adotar sistemas verticais de condução, realizar o desponte e a desbrota de ramos e utilizar retardadores de crescimento para controlar o vigor excessivo. Para as condições das regiões Leste e Noroeste do Estado de São Paulo, essa condição é mais preocupante no período entre florada e estádio de "grão-de-ervilha", principal época de diferenciação, necessitando maior atenção por parte do viticultor.

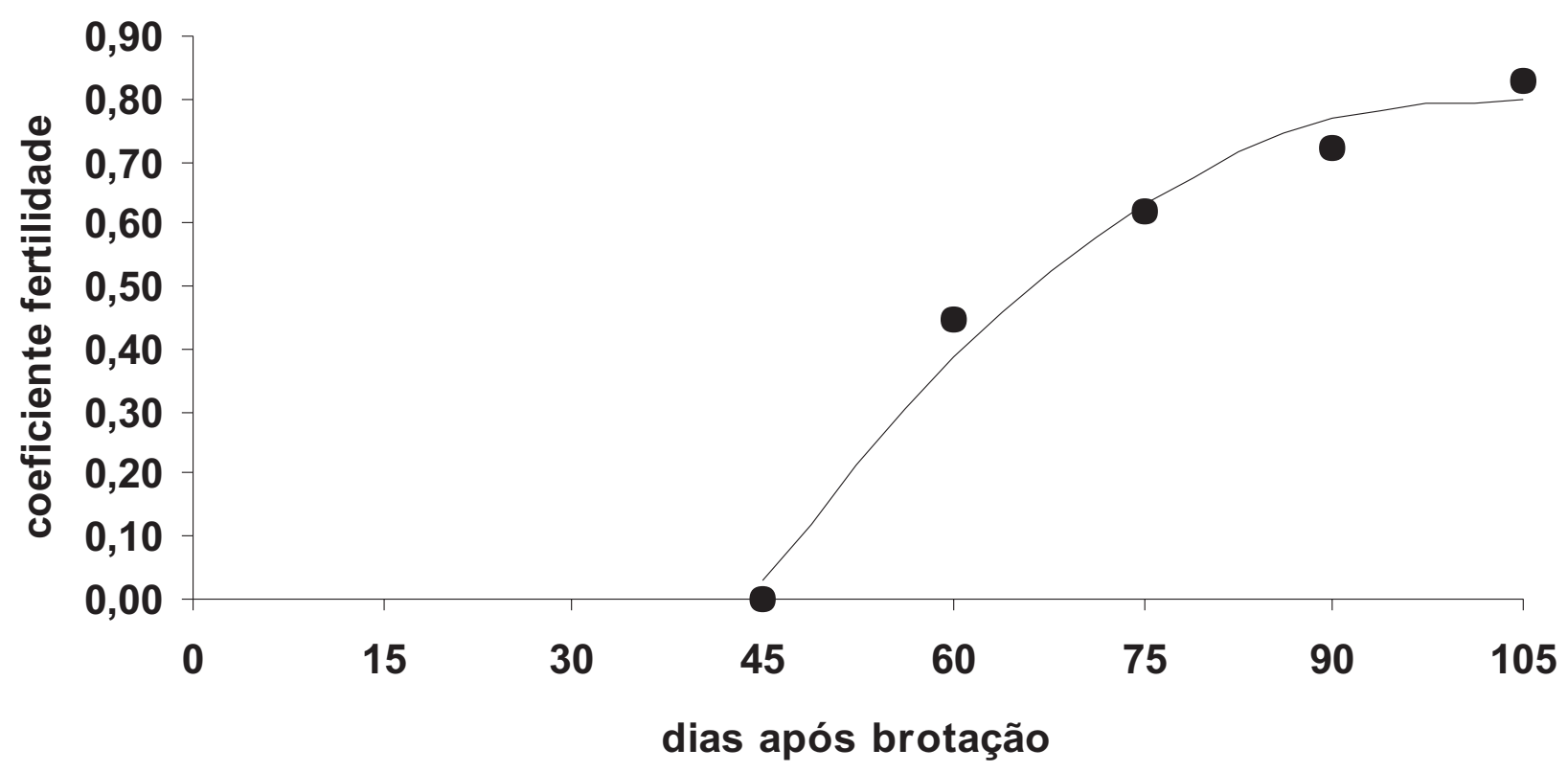

Figura 4. Coeficiente de fertilidade (relação entre número de primórdios de inflorescência/número total de gemas) de videiras cv. Itália. 


\section{CONCLUSÕES}

1. A diferenciação de primórdios de inflorescência em videiras cv. Itália nas regiões de Jundiaí (SP) e Jales (SP) ocorreu principalmente entre 45 e 75 dias após a brotação, correspondendo aos estádios fenológicos de floração e "grão-de-ervilha" respectivamente.

2. O coeficiente de fertilidade de gemas aumentou até os 105 dias após a brotação, com a formação de até dois primórdios de inflorescência por gema.

3. Em Jales, obteve-se maior porcentagem de gemas férteis do que em Jundiaí.

\section{REFERÊNCIAS}

BALDWIN, J.G. The relation between weather and fruitfulness of the Sultana vine. Australian Journal of Agricultural Research, Victoria, v. 15, n. 6, p. 920-928, 1964.

BOSS, P.K.; BUCKERIDGE, E.J.; POOLE, A. et al. New insights into grapevine flowering. Functional Plant Biology, Victoria, v. 30, n. 6, p. 593-606, 2003.
BOTELHO, R.V.; PIRES, E.J.P.; TERRA, M.M. Efeitos do cycocel na fertilidade de gemas e no crescimento dos ramos de videiras cv. Itália (Vitis vinifera L.). Revista Brasileira de Fruticultura, Jaboticabal, v.26, n.1, p.78-81, 2004.

BUTTROSE, M.S. Fruitfulness in grape-vines: The response of different cultivars to light, temperature and daylength. Vitis, Siebeldingen, v.9, p.121-125, 1970.

CHADHA, K.L.; SHIKHAMANY, S.D. The grape: Improvement, production and post-harvest management. New Delhi: Malhotra Publishing House, 1999. 579p.

GERRATH, J.M. Developmental morphology and anatomy of grape flowers. Horticultural Reviews, New York, v.13, p.315337, 1992.

MORRISON, J.C. Bud development in Vitis vinifera L. Botanical Gazette, Chicago, v.153, n.3, p.304-315, 1991.

MULLINS, M.G.; BOUQUET, A.; WILLIAMS, L.E. Biology of the grapevine. Cambridge: University Press, 2000. 239p.

SHIKHAMANY, S.D. Physiology and cultural practices to produce seedless grapes in tropical environments. In: CONGRESSO BRASILEIRO DE VITICULTURA E ENOLOGIA, 9, 1999, Bento Gonçalves. Anais... Bento Gonçalves: EmbrapaCNPUV, 1999. p.43-48.

SRINIVASAN, C.; MULLINS, M.G. Physiology of flowering in the grapevine - A review. American Journal of Enology and Viticulture, Davis, v.32, n.1, p.47-63, 1981. 